\title{
The 193 call center, a meaningful public service!
}

\author{
Maud Eickhoff ${ }^{\mathrm{a}}$, Laerte Idal Sznelwar ${ }^{\mathrm{b}}$ \\ ${ }^{a}$ Student in the Master's Program of the Department of Production Engineering of the Polytechnic School of the \\ University of São Paulo, Brazil. \\ ${ }^{\mathrm{b}}$ Ph.D. Professor with the Master's Program of the Department of Production Engineering of the Polytechnic \\ School of the University of São Paulo. , Brazil.
}

\begin{abstract}
This article is the first part of an on-going ergonomic work analysis with the emergency services call center set up by the Fire Department of the Military Police of São Paulo. The final objective of the research is to identify the prescribed task, the real work executed and strategies used by workers to meet the demands of the job. Starting by identifying the tasks and activities developed, this article analyzes the work of the emergency services call center which is of vital importance to the organizational structure, since it is the start point for the process that results in fulfilling the corporation's mission.
\end{abstract}

Key words: fire department service, rescue service management, the emergency services call center.

\section{Introduction}

The call center service has been the subject of many ergonomics studies, motivated mainly by the consequences this work has for the health of those who carry it out and have often stressed that no significance has been attributed to this activity, either by workers or by the organizations.

However, for some organizations, the call center service is essential, since based on this activity the resources that allow the organization to fulfill its mandate are activated. That can be observed at the telephone service support the Fire Department of the Military Police of São Paulo provides to the public, through the 193 Call Center.

This call center gives out information, provides guidance and when necessary records the events that require further action, and in those cases, manages the operations. The activity is carried out through the integration of two teams: the first acts in direct contact with citizens (called the Emergency Call Answering Post - "P.A."), and the second team (Dispatching Station - "P. D.") is responsible for managing rescue operations, safety and any other interventions through to their conclusion.
The analytical method used for this study was Ergonomic Work Analysis (EWA) [9], and this article presents the results of the task analysis and some considerations about the activity performed. The data were obtained from the various electronic portals (sites of the Fire Department of the São Paulo State Military Police, the São Paulo state government and the Brazilian Institute for Geography and Statistics - IBGE), and interviews with the COBOM commandant of the 193 Emergency Services Call Center, and information obtained from the support teams. It was also possible to informally observe in the service center room, which allowed informal interviews with workers at the Center. The consolidation of data was presented to the COBOM Commandant and to the support teams and validated by them.

In parallel, a bibliographic study was carried out, going in depth into the concepts involved in an ergonomic work analysis, and reviewing studies that presented different approaches to the service centers, including the organization of work and the strategies adopted for workers to fulfill their activity.

This article was structured in order first to analyze the ergonomic concepts used in studies of the call centers and to identify the main difficulties workers faced in carrying out their activities. Later, the work 
organization at the 193 Call Center is described, identifying the prescribed tasks and the activities carried out, based on the elements available at this initial stage of the study in progress.

The final section includes the following stages, the objectives and the methods that will be used in the development of the study.

\section{Ergonomic Work Analysis - EWA - and its contribution to the study of the emergency services Call Center}

This study intends to take full advantage of opportunities that the ergonomic work analysis method offers in this specific work situation, pointing out how consideration of ergonomic proposals could contribute to improving working conditions.

Ergonomic Work Analysis -EWA - is a method structured in various stages and activities, which are constructed, validated and/or refuted during process of analyses. The central principle of EWA is to-show the complexity of the work, and to understand it as the inter-relationship of different variables in a specific context.

Emergency call center activities have received growing attentions, from organizations as well as academia. This is a complex and dynamic service, which demands interaction of multiple variables in real time and includes the relationship of agents involved: workers, service users and managers.

Management of emergency services call centers should take into consideration that real work situations are not totally predictable and that the variables involved are different in each situation that arises and cannot be totally known or controlled. Thus, importing management paradigms for industrial activities for this work has limitations, since the simplification of processes, an emphasis on productivity and quality, and the rigidity of the scripts which characterize these models, do not contemplate real dynamic situations.

For this activity to be considered strategic to any organization, its structure should provide adequate conditions for its development. Especially with respect to services provided to citizens by public agencies, the lack of alternatives to the service and the social function of the organization should also be considered. The failure to satisfy the expectations of the users can result in high costs in human and material terms Work organization should contemplate the physical conditions, technological resources, and the activities of the workers directly or indirectly involved in service delivery; it should have the flexibility needed to allow it to fit the different situations that come up and, at the same time, contemplate minimal prescription to guarantee the quality of the service provided. Whether or not it meets the objectives is shown in a different way by each of the agents involved: for the workers the effects manifest themselves on their health, quality of life and efficiency, for the user, in whether or not it meets their expectations, and for the organization in the efficacy and efficiency of the service provided.

\section{Work organization at the 193 Emergency Call Center of the Department of the Military Police of São Paulo}

\subsection{Region serviced of the 193 Call Center and the organizational structure of the Fire Department}

The present study was developed at the Fire Department located in the Clóvis Bevilácqua Square in downtown São Paulo, at a time when it was undergoing a process of restructuring. Until 2009, the emergency telephone service of the Fire Department of the São Paulo Metropolitan Area was decentralized and the territorial area serviced of the 193 Emergency Call Center was restricted to the capital. Beginning in 2009, the services of the other 38 cities in the metropolitan region were gradually incorporated. This centralization process was concluded by the end of 2010, thus extending its area serviced from 1,523 $\mathrm{km} 2$ to $797,729 \mathrm{~km} 2$, and increasing the population served from 10,886,518 (count as of January 4, 2007) to $19,672,583$ people in 2010 , according to from the IBGE'data $^{[10]}$.

Accommodating the system to this new configuration has been made more difficult by the lack of a history against which to measure the dimensions of the increased demand, and thus it is being implemented based on projected needs, taking into account the organizational possibilities.

Currently, the 39 cities of the São Paulo Metropolitan Region are being managed based at the 193 Central by four groups of firefighters headquartered in the capital and three groups of firefighters located in the Metropolitan Region (in the cities of Barueri, Guarulhos and Santo André).

The COBOM (Fire Department Command activity's management department, is subordinate to the General Command of the Fire Department, which in 
turn, is a department of the Military Police whose Commander is part of the Public Safety Department of São Paulo State.

The Fire Department is a military organization, and the emergency call center workers are recruited from among firefighters who worked in the streets, considered an essential prerequisite by managers to qualify for a job in the service. The firefighters allocated to management of occurrences have experience as rescue workers and know well the geographic area they are administering.

Each of the two teams from the 193 Emergency Call Center (PA's and PD's) have a permanent supervisor, as well as support from the head of CO$\mathrm{BOM}$, and a permanent medical assistance in the room. The Center has a direct communications channel with the Emergency Medical Service ("SAMU” - Serviço Médico de Urgência), which answers to 192 phone and with the Military Police, who answer the 191 line.

\subsection{Service attendance cycles}

The 193 Emergency Call Center service involves service relationships. Service can be defined as the way the organization and resources are mobilized to interpret, comprehend and manage changes in the activities of service users ${ }^{[17]}$. Service delivery by the 193 Center involves the relationship of individuals to the organization. The service is activated when it receives a citizen's request to intervene in some reality or problem. ${ }^{[14]}$

Service delivery can be understood as a process, which is developed over a period of time, involving multiple components and encounter points, and this process is developed over a cycle where the end of a meeting point or of a cycle leads to the next cycle. ${ }^{[15]}$

Work at the call center is a process that develops over the life of a cycle. The service cycle begins by identifying user needs to make contact with the organization. The first impact, favorable or not, is in the ease of making contact, that is, it begins before the real service starts. ${ }^{[1]}$

In the beginning, what is important is the attendant's ability to communicate, to interpret, the ease access to the information to help the caller, and how the work organization makes available the necessary resources to provide the service.

COBOM's activities are divided into two cycles. The first cycle starts when the person calls in and an attendant from the Emergency Call Center team answers. This team, presently consisting of 10 post service ("PA"), identifies the request, provides information when necessary, offers guidance and when it determines that the matter requires mobilization of resources, it write down the event, and tries to get the best, most complete information possible out of the speaker, and then completes its services providing the initial guidance the caller should follow. When the event is recorded, a router automatically sends it to the Dispatching Station (PD) the second service cycle, which will monitor the event until the workers and equipments sent into action return to their base.

Since these are activities with different characteristics and that make different demands on workers, they are analyzed separately, even though they are complementary, are carried out by teams working in the same place, who are continuously in contact and if necessary can be reallocated among the work stations.

\subsubsection{Cycles of service at the Emergency Call Answering Post (P.A.)}

The operators at the Emergency Call Answering Center (PA) are in direct contact with callers. Their jobs involve mobilizing several cognitive resources, such as memory, the ability to pay attention and to problem solve. Workers must have knowledge of the situations reported, must have good communications techniques that allow them to obtain important information and disregard anything that doesn't contribute to understanding of the situation. They have to be able to transmit instructions and information precisely and accurately, and to establish good communication with callers. Moreover, they must be able to record adequately the event, and to produce the best information possible for those who will manage the events that require action.

The Answering Post workers answer around 5 million calls per years. There are 10 post of attendance, which are staffed by teams with different work shifts.

Calls are received about diverse situations, ranging from motor vehicle accidents, people being run over, household accidents, falling trees, animal attacks, accident with electric wires, fires, burns, drownings requests to transport the obese and elderly, are among the diverse requests reported to risk of life or preservations of the environment. In addition to this wide range, a large number of calls make requests that have nothing to do with the Fire Department's activity, such as requests for medical services, prank calls (representing $30 \%$ of calls), and others. 
Sometimes workers have difficulty in convincing for callers that their requests cannot be met. In one situation witnessed during the study, a woman requested a team to catch a stray dog. The firefighter who answered the call tried to discover whether the animal represented a threat to people. Learning that there was no immediate risk, the women was then oriented to contact the city's office of animal control, which is responsible for catching stray animals. The woman did not accept this guidance and believed that her request should be attended to, and the firefighter had to repeat the reasons for not doing so three times. After the call was over, he reported that in addition to not being part of the work of the fire department, the service requested, catching animals results in yet another problem, i.e., looking for somewhere that would take the animal in, since the city shelters were always overcrowded and refused more animals.

In another situation witnessed which portrayed the diversity of callers' requests, a very upset woman called complaining that she had called over $30 \mathrm{~min}$ utes earlier to request help for her father who was having a high blood pressure attack. The firefighter checked whether any such request had come into the Center and very patiently explained to her that it was probable she had called the Emergency Medical Service (SAMU). He asked whether she was in shape to call the 192 number, and then only got off the phone when she had calmed down and assured him that she was able to call the 192 phone.

The firefighter didn't use the script defined by COBOM during this call. This document exists, however it is out of date and there is an understanding among managers and operators that it is not indispensable to carrying out their jobs, considering the variety of situations encountered. The worker is the responsible for the attendance and when faced with a difficulty has recourse to a colleague, a supervisor, a doctor or to the comander of the shift/shift commander.

When there is a response that involves mobilizing resources, it will be referred to the computerized system of the Dispatching Station (PD) responsible for its management. If the matter dealt with does not require follow up, the call is saved and the Answering Post (PA) is ready to receive a new call. Thus, the closure of this service cycle occurs when the call is finalized and a new cycle begins.

\subsubsection{Service cycles at the Dispatching Station (PD)}

The service cycle of the Dispatching Station (PD) begins when the incident is recorded by the Answering Post (PA), and sent to the computerized system by the worker responsible for dispatching resources to carry out the requested operation.

There are presently seven Dispatching Station (PD) in the 193 Emergency Call Center, and each responds for a defined geographic areas. The commandant of the P.D. is usually chosen from among the firefighters at the Center who are already working in rescue in the region, which helps with decision making regarding resource mobilization. There are, on average about 500 calls per day served.

Even though they do not have direct contact with the public as do the workers at the Answering Post, these workers must also mobilize their cognitive resources, related to work memory and interpretation, work up information and develop strategies to solve the problem presented and to manage the available resources.

At the beginning of the service cycle, workers receive and identify the event, develop a strategy to deal with it, define the resources needed, and check on available resources (which do not always match).

Based on the assessment, the process of activating resources started. These workers alert the firefighters headquartered which has the best possible conditions to respond to the event, using criteria such as the nature and urgency of the call, the proximity of the place, and the availability of equipment or personnel. Each P.D. has a given number of departments in its geographic area and monitors the vehicles, equipment and rescue teams available at each one. Sometimes one of the P.D. will request help from another, which in allocating its equipment, vehicles or personnel will have its area "covered" by another P.D. if necessary.

Workers at these posts permanently monitor all the occurrences that they are managing simultaneously, and in addition to inputting them into the computer system, the vehicles used for each one of the occurrences and those available for use, they also use a magnetized board located beneath the video monitor, where they create a kind of backup for resources. In this board an "informal code", where workers can compensate for a flaw in the system that doesn't permit the register of vehicles when they go back to department lots. By inclining the rectangle that represent the vehicles to the right or left, controllers know whether the cars can be used or need to be re- 
filled, cleaned or something else prior to being used again.

This team of workers has support from commandant of the shift and from a doctor. The Commander Shift follow the management of all the occurrences, and among their responsibilities is to determine allocation of resources among the P.D. and to cover the areas that have ceded resources, manage rest breaks, shift changes and any occasional changes in the functioning of the service.

Among the doctors' functions is to provide support when rescue workers report to the Base Center that victims require urgent medical services, and have to be dealt with before being sent to the hospital. The doctor dispatches a medical team to the place or intercepts the vehicle that is transporting the victims, or can helicopter rescue. Moreover, the doctor periodically sends a report on the situation of all the hospitals to the P.D., so that those managing events can direct victims to the best hospital according to the medical specialty required for each case. This communication takes place by using a table, where the different Emergency Rooms for each region are printed out along with their medical specialties and the doctor manually fills in the availability for each situation.

The large amount of information and the use of different resources to monitor events, as well as their great variety, reveal the complexity of this cycle of service. In practice, workers still face difficulties when available resources are not sufficient to deal adequately with the event, and with the limitations of the computer system that requires operators to adapt resources to achieve the reliability needed to perform their jobs.

The street teams are in communication with the P.D. throughout the process of responding to the call. There are some standardized procedures for transmitting information. For example, in a witnessed incident, the communication established between the emergency response team on the street and the P.D. (recorded on the computerized system and on the backup system) was: the vehicle left headquarters, the vehicle arrived on location, the victim was located, the victim was identified or had the described characteristics, the victim's health condition and the need for additional resources was reported, the street team received hospital orders regarding where to send the victim, the victim was referred and delivered to the hospital, the vehicle is returned to the lot (and in what shape), the vehicle was located in the department lot, the vehicle was available for use.
Closure of this service cycle occurs when the vehicles and teams involved return to the department lot. However, since several calls are being managed simultaneously, workers do not have a break between one call and another, since when one service closes out, others are at different stages in the cycle and some are being initiated. This is a continuous process with an intense workload.

\section{The demand for ergonomic analysis at the $\mathbf{1 9 3}$ Call Center}

Activities carried out by the 193 Call Center teams expose workers to different events that demand competencies that allow to portray the diverse situations that come up, in order to transmit information, anticipate actions and provide support for decisions, even in situations in which there is incomplete knowledge of the variables involved.

It is desirable that workers at the Emergency Call Answering Post (PA) are in conditions to decide quickly, have the possibility to pay attention to the on-going dialogue, a system that affords good conditions to assess the dimensions and extent of the situation reported, and the necessary information to identify relevant in the reports of the citizen reports, which will guide resulting actions and even to decide which situations will or not require follow up in the field.

In managing occurrences at the Dispatching Station (PD), workers need always to understand and interpret the reported event, and based on their experience to activate the resources needed to deal with the event, manage the available resources, monitor at a distance the work undertaken, implement corrections or make changes to decisions taken earlier based on information they receive, and to seek additional support whenever necessary.

In management these activities is required that the designated service be completed, requiring the workers involved to associate different variables. Some of these can be administered in the internal environment of work development, such as organizing work shifts, internal communications, and organization of work teams. However other variables are external to the activity, such as those that involve legal limitations, regulations that must be respected, policies for recruitment, selection and training, budget constraints, and what's happening in the field, as for example, traffic conditions, climate and the characteristics of 
the situation that the in intervention group face when arriving at the local of the event.

This article presents the context in which the Emergency Call Service Center of the Fire Department of the São Paulo State Military Police operates. It is the initial stage of a process of ergonomic work analysis, whose final objective will be to understand the relationship of the variables involved in carrying out the work, the resources used by workers in daily life and opportunities to make contributions to transforming this work.

\section{References}

[1] Abrahão, J. et al. Introdução à ergonomia: da prática à teoria. [Introduction to Ergonomics: From Theory to Practice] São Paulo: Blucher, 2009.

[2] Abrahão, J. et al. Trabalhar em centrais de atendimento: a busca de sentido em tarefas esvaziadas. [Working in Call Centers: The Search of/for Meaning in Tasks Devoid of Meaning] Revista Brasileira de Saúde Ocupacional, São Paulo, 31 (114): 97-112, 2006

[3] Abrahão, Júlia I; Torres, Camila C. Entre a organização do trabalho e o sofrimento: o papel da mediação da atividade. [Between Work Organization and Suffering: the role of mediating activities] Revista Produção, v. 14, n 3, p. 067-076. Set/Dez/ 2004.

[4] Corpo de Bombeiros do Estado de São Paulo. Disponível em: http://www.bombeiros.sp.gov.br. 2011.

[5] Dejours, Christofer. Avaliação do trabalho submetida à prova do real - Crítica aos fundamentos da avaliação. [Work Assessment Subject to Reality - Criticism on the Assessment Fundaments/Critique of Assessment Fundamentals] Cadernos de TTO 2. Org. Laerte Idal Sznelwar, Fausto Leopoldo Mascia. São Paulo. Blucher, 2008

[6] Daniellou, F. A Ergonomia em busca de seus princípios: debates epistemológicos. [Ergonomics in Search of its Principles: epistemological debates] São Paulo: Edigar Blücher, 2004.

[7] Falzon, Pierre. Ergonomia. [Ergonomics] Editora Blucher, 2007.

[8] Ferreira, Mário César. Serviço de Atendimento ao Público: O que é? Como analisá-lo? Esboço de uma Abordagem Teórico Metodológica em Ergonomia. [Call Services for the Public: What are they? How can they be analyzed? Outline for a Theoretical Approach with an Ergonomic Method] Revista Multitemas, $\mathrm{n}^{\mathrm{o}}$ 16, maio, 2000. pp.; 128-144. Campo Grande MS, UCDB.

[9] Guerin, F et, al. Compreender o trabalho para transformá-lo. [Understanding Work in order to Transform it] Edgard Blucher, São Paulo, 2001.

[10] Instituto Brasileiro de Geografia e Estatística - IBGE. Disponível em: http://www.ibge.gov.br. 2011.

[11] Miciak, Alan; Desmarais, Mike. Benchmarking service quality performance at business-to-business and business-toconsumer call centers. Journal of Business \& Industrial Marketing. Volume: 16 Number: 5, Year: 2001. pp: 340-353.

[12] Polícia Militar do Estado de São Paulo. Disponível em: http://www.policiamilitar.sp.gov.br .2011.

[13] Secretaria de Estado dos Negócios de Segurança Pública de São Paulo. Disponível em: http://www.ssp.sp.gov.br. 2011.
[14]Torres, Camila Costa. A Atividade nas Centrais de Atendimento: Outra Realidade, as Mesmas Queixas. [Call Center Activities: Another Reality, the Same Complaints] Dissertação apresentada ao Instituto de Psicologia da Universidade de Brasília, UNB, Brasília, 2001

[15] Voss, Chris; Zomerdijk, Leonieke. Innovation in Experimental Service: an Empirical View. DTI (ed.). Innovation in Services. London. 2007. pp. 97-134.

[16] Wolff, Marion; Sperandio, Jean-Claude. O trabalho em condições extremas. [Work under Extreme Conditions] in: FALZON, Pierre. (org.). Ergonomia. Editora Blucher, 2007. (p.85-95)

[17]Zarifiana, P. Valor, organização e competência na produção do serviço. Esboço de um modelo de produção do serviço. [Value, Organization and Competence in Service Production. Outline for a Service Production Model] In: Salerno, M.S. Relação de Serviço, Produção e Avaliação. Editora SENAC: 2001 . 